\title{
The Relationship Between the Meaning of Life, Psychological Well-Being, Self-Care, and Social Capital, with Depression and Death Anxiety in the Elderly Living in Nursing Homes: The Mediating Role of Loneliness
}

Majid Yousefi Afrashteh ( $\nabla$ yousefi@znu.ac.ir)

University of Zanjan

Mohammad Reza Majzoobi

University of Siegen

Parisa Janjani

Kermanshah University of Medical Sciences

\section{Simon Forstmeier}

University of Siegen

\section{Research Article}

Keywords: Meaning of life, psychological well-being, self-care, social capital, depression, death anxiety, Iran

Posted Date: January 10th, 2022

DOI: https://doi.org/10.21203/rs.3.rs-1217744/v1

License: (c) (1) This work is licensed under a Creative Commons Attribution 4.0 International License. Read Full License 


\section{Abstract}

The current study aims to investigate the meaning of life, psychological well-being, self-care, and social capital, with depression and death anxiety in the elderly living in nursing homes through the mediating role of loneliness. The statistical population included all the elderly aged at least 60 years living in Tehran, Qazvin and Zanjan, Iran in 2020, among whom 489 (273 men and 216 women) were selected using convenience sampling method. Participants filled out Steger's Meaning of Life, Ryff and Singer's Psychological Well-Being Scale, Söderhamn et al.'s Self-Care Ability, Nahapiet and Ghoshal's Social capital, Beck's depression, Templer's Death Anxiety, Russell et al.'s Loneliness questionnaires. The results indicated that there is a significant relationship between the meaning of life, psychological well-being, self-care, and social capital, with depression through the mediating role of loneliness. Besides, there was a significant relationship between the meaning of life, psychological well-being, self-care, and social capital, with death anxiety through the mediating role of loneliness. Moreover, the results of path analysis showed that the hypothesized model of the current study has an excellent fit in the study sample.

\section{Introduction}

The aging population is of essential interest in global population trends. The 65 -year-olds and older individuals accounted for $9 \%$ of the population in 2019 , which is predicted to reach $12 \%, 16 \%$, and $23 \%$ until 2030,2050 , and 2100 , respectively (1). Given that the ratio of elderly people in countries with a high level of income is currently greater than that of others, it is predicted that the most significant change will take place in countries with a low and medium level of income, and $80 \%$ of elderly people will live in developing countries until 2050 (2). According to the census taken in 2016, 3.9\% of the population of Iran (more than seven million individuals) were 60 years and older. Besides, according to international estimations, the elderly population of Iran will grow at a higher rate than in other regions (3). The acceleration in global population aging has raised some concerns regarding the mental health of the elderly. Aging can increase the risk of mental issues (4). According to the World Health Organization (WHO) reports, more than one-fifth of people aged 60 years and over suffer from at least one psychological disorder (2). Studies also indicated that the prevalence of psychological disorders among the elderly is higher than that in adults (5), among which dementia, depression and death anxiety are the most common (6).

\section{Mental health in old age}

Depression and anxiety are the most common psychological disorders in old ages (7). Systematic reviews have reported the prevalence of depression symptoms among the elderly to be $10 \%$ to $20 \%$ worldwide (8) and to be $43 \%$ in Iran (9). The prevalence of death anxiety among the elderly is also arguable. In some other studies, death anxiety is also reported to be high due to health problems, mobility limitations, and dependence on others (9). 
Depression, known as the essential factor of inability worldwide, is recognized by symptoms, such as sadness, reduced level of interest or enjoyment, feeling of guilt, sleeping or appetite disorders, feeling of tiredness, and reduced concentration level (10). The negative effects of depression on mental and behavioral states include a vast range of changes in feeling worthy, hopefulness, self-care behaviors, and quality of life (11). Studies have indicated that depression is correlated with fundamental variables in the elderly, such as cognitive impairment (12), chronic physical pain (13), interpersonal problems, daily activities, and health-related quality of life (14), reduced health-oriented behaviors (15), reduced quality of life (16), and reduced psychological mental health (17).

As a natural experience of humans, death anxiety includes thoughts, fears, and emotions pertinent to the end of life (18). Even though death is a biological and psychological reality, thinking about it is fearful and a vast majority of individuals prefer not to think about it since death fear and anxiety are unpleasant (19). Although it is normal to experience death anxiety to some extent, a high level of death anxiety in the elderly is associated with different problems, such as low life expectancy (20), depression (21), and anxiety disorders (22). Over the past years, the role that different variables play in predicting depression have been investigated, such as the meaning of life (23), defined by Steger and Frazier (24) as an individual's ability to perceive life, self and the external world, and being adjusted to it; psychological well-being $(25,26)$, defined by Karademas $(27)$, as emotional and cognitive reactions to perception of personal features and abilities, sufficient advance, efficient interaction with world, desirable connection and relationship with the community and positive advancement over time; selfcare (28), defined by Chen et al. (29) as a self-development activity in order to the maintenance of physical and mental health; social capital (30-32), defined by Putnam (33) as interpersonal connections, social networks, trust norms, mutual action and reaction resulting from the mentioned connections. Besides, the meaning of life (34), psychological well-being (35,36), self-care (37), and social capital (38), have been studied as the predictors of death anxiety.

Although the above-mentioned studies have indicated the relationship between meaning of life, psychological well-being, self-care, and social support with depression and death anxiety in the elderly, there is found little evidence indicating the pathways through which the mentioned variables may be related to depression and death anxiety. For instance, Zhang et al. (34) figured out that the meaning of life is related to depression through the mediating role of self-esteem in the elderly. Besides, Sun et al (31) indicated that social capital is correlated to depression through the mediating role of life satisfaction in the elderly. One variable that may play a determining role in this regard seems to be loneliness.

\section{Loneliness and mental health}

Loneliness is an upsetting state felt when there is a distance between people's desired interpersonal relationships and the relationships they currently have (39). Loneliness is a pervasive phenomenon (39) and evidence indicates that $20 \%$ to $40 \%$ of the elderly have reported that suffering from 
loneliness (40). This undesired experience is reported to be between $19.6 \%$ to $34 \%$ among people aged 65 years and over in the United States of America (41). Indeed loneliness is an essential index of mental health and quality of life in the elderly that widely increases the probability of physical and mental diseases during old ages (42). Accordingly, on the one hand, the results of studies have indicated that loneliness is significantly correlated with meaning of life $(43,44)$, psychological well-being $(45,46)$, selfcare (47), and social capital $(48,49)$. On the other hand, loneliness seems to be a significant predictor of depression (50-52) and death anxiety (53-55).

\section{Aim of the present study}

According to the studies having considered the relationship between the meaning of life, psychological well-being, self-care, and social capital with loneliness as well as the relationship between loneliness with depression and death anxiety, it seems that the relationship among these variables has been independently investigated and the results have confirmed the presence of a significant relationship among them. However, few studies have investigated the role of mediating variables that serve as a bridge between the mentioned variables, and there is still a huge gap in this regard in the literature of field of inquiry. According to the mentioned statistics regarding the acceleration rate of Iran population toward old age, studies on different fundamental psychological variables in this field could enrich the literature. The presentation of causal models regarding essential variables of old age may cause the therapists working in this field to gain a profound knowledge regarding the interaction between these variables. Accordingly, proposing a comprehensive model, this study aims to investigate the role that an essential parameter, such as loneliness, plays in the relationship between meaning of life, psychological well-being, self-care, social capital with depression and death anxiety in the elderly. The hypotheses of this model are listed as follows. (1) The meaning of life is correlated with depression through loneliness. (2) Psychological well-being is correlated with depression through loneliness. (3) Self-care is correlated with depression through loneliness. (4) Social capital is correlated with depression through loneliness. (5) Meaning of life is correlated with death anxiety through loneliness. (6) Psychological well-being is correlated with death anxiety through loneliness. (7) Social capital is correlated with death anxiety through loneliness. The model proposed by this study is indicated in Figure 1.

\section{Method}

The method of the present study was correlational of path analysis type. The statistical population included all the elderly living in Iran in 2020. To recruit the statistical sample, three states of Tehran, Qazvin and Zanjan, Iran were selected using convenience sampling method, in which 12 daily nursing homes were chosen randomly. In the next step, 530 aged people were selected from the predesignated 12 nursing homes, among whom 489 were analyzed after exclusion of distorted questionnaires. Regarding the sample size, it is worth noting that Stevens (56) stated that considering 15 cases for each predictor variable in the multiple regression analysis by the conventional method of the minimum squared standard is a good rule of thumb. Based on this, it can be stated that because path analysis in some 
respects is completely related to multivariate regression, 15 cases for each variable measured in path analysis is not irrational (56). Loehlin (56) states that for models with two or four factors, the researcher must plan to collect at least 100 or more, for example, 200. Also, the sample size was determined according to the Cochran's formula for a community with an unknown number, 364 people. Inclusion criteria included (1) age over 60 years, (2) being literate, (3) the absence of using psychiatric drugs, (4) the absence of chronic illness, (5) the absence of experience of any stressful event in the last six months. Out of 489 participants of this study, 273 (56\%) were men and $216(44 \%)$ were women, among all of whom $176(36 \%)$ were in the age group of 60-65 years, $146(30 \%)$ were in 66-70, $105(21 \%)$ were in 71-75, and 62 (13\%) were in 76-80. Among participants, 45 (9\%) were single, 137 (28\%) married and 307 $(63 \%)$ divorced or widow. The marriage length was $41.49 \pm 7.93$. The education level was elementary school in 103 (21\%), junior high school in 109 (22\%), senior high school in 130 (27\%), and higher education in $50(10 \%)$ of the participants, and eventually, $97(20 \%)$ of the participants were illiterate.

\section{Measures}

The Meaning of Life Questionnaire. This scale, developed bySteger's (57), includes ten items that measure two components of presence of meaning in life and search for meaning in life. Each item is scored on a 7-point Likert scale, ranging from "completely false" to "completely true". The minimum and maximum scores are 10 and 70, respectively, with higher score indicating higher level of the meaning in life and search for the meaning of life, and vice versa. Studies have confirmed the validity and reliability of the questionnaire and its convergent and differential validity $(58,59)$. For two components of the scale, Steger et al. (60) reported internal consistency with alpha coefficients between 0.82 and 0.87 . They also reported the result of the reliability of two mentioned components through test-retest method with a time interval of one month to be 0.70 and 0.73 , respectively. In Iran, the reliability of the questionnaire was reported to be between 0.86 and 0.87 , and its validity is confirmed through confirmatory factor analysis $(61,62)$. The reliability of this questionnaire in the present study was 0.74 , using Cronbach's alpha method.

Psychological Well-Being Scale. This scale,developed byRyff and Singer (63), includes 18 items, evaluating the subscales of autonomy, environmental mastery, personal growth, positive relations with others, purpose in life, and self-acceptance on a 6-point Likert scale, ranging from "strongly disagree" to "strongly agree". The minimum and maximum scores are 18 and 108, respectively, with higher score indicating higher psychological well-being and vice versa. Ryff and Singer reported that the correlation of this test with its 84 -item version is between 0.70 and 0.89 , and that the internal consistency of the scale is 0.56. In Iran, Khanjani et al. (64) obtained its internal consistency using Cronbach's alpha coefficient to be $0.51,0.76,0.75,0.53,0.73$, and 0.72 for subscales of self-acceptance, environmental mastery, positive relations with others, purpose in life, personal growth, and autonomy, respectively. Besides, the total Cronbach's alpha coefficient was obtained to be 0.71 . The reliability of this questionnaire in the present study was 0.82 , using Cronbach's alpha method. 
The Self-Care Ability Scale for the Elderly (SASE).This scale, designed by Söderhamn et al. (65), has 17 items. Each item is scored on a 5-point Likert scale, ranging from "strongly agree" to "strongly disagree". The minimum and maximum scores are 17 and 85, respectively, with higher score indicating higher level of the self-care, and vice versa. A score lower than 69 indicates a low level of self-care ability, and a score equal to or higher than 69 indicates a high level of self-care ability. Söderhamn et al. (66) reported the validity and reliability of this scale to be 0.68 and 0.88 , respectively. Besides, Hashemlo et al. (67) reported the validity and reliability of the current scale equal to 0.86 and 0.743 in Iran. The reliability of this questionnaire in the present study was 0.73 , using Cronbach's alpha method.

Social Capital Scale.This scale, designed according to Nahapiet and Ghoshal's (68) model, measures the level of social capital through three subscales of structural, cognitive, and relational elements. This scale consists of 15 items to measure social capital on a 5-point Likert scale, ranging from "very low" to "very high", with higher score indicating higher level of social capital, and vice versa. Ghalavandi et al. (69) reported the Cronbach's alpha coefficient of this scale to be $0.74,0.78$, and 0.79 for each one of above-mentioned three subscales of social capital. The reliability of this questionnaire in the present study was 0.79 , using Cronbach's alpha method.

Beck's Depression Questionnaire (BDI-13). This questionnaire was published by Beck and Steer in a new form in 1987 (70). The items of this questionnaire are obtained from observing and summarizing the attitudes and symptoms of depressed patients. Beck's depression inventory consists of 21 items and the short form consists of 13 items. In the 13-item form, applied in the current study, the score varies between zero and 39. There are four questions for each component, and the value of scores is between zero and 3 . The score of zero indicates mental health, and the score of 3 indicates major depression. The validity and reliability of this test are reported to be acceptable (71). In Iran, Tarsafi et al. (72) reported that the reliability coefficient of the depression scale is 0.87 using Cronbach's alpha method. The reliability of this questionnaire in the present study was 0.76 , using Cronbach's alpha method.

Templer's Death Anxiety Scale (DAS). This scale, designed by Templer (73), consists of 15 items that measure participants' attitudes toward death. Participants answer the questions by "Yes" and "No" to indicate that suffer and do not suffer from death anxiety, respectively. Accordingly, scores of this scale vary between zero and 15, with higher scores indicating individuals' higher levels of death anxiety, and vice versa. DAS has been employed in different studies worldwide for measuring death anxiety. In the main culture, test-retest coefficient of the scale with an interval of one month was reported to be 0.83 (73). In Iran, Rajabi and Bahrani (74) reported the reliability of the DAS, through Cronbach's alpha, split-half, and two-week test-retest to be $0.6,0.52$ and 0.63 , respectively. Rajabi and Bahrani have also reported the validity of DAS through considering its correlation with Dickstein's Death Concern Scale (DSC), the Collett-Lester's Fear of Death Scale (CL-FODS), the Abdel-Khalek's Reasons for Death Fear Scale (RDFS), the Abdel-Khalek's Death Obsession Scale (DOS) to be 0.52, 0.38, 0.50 and 0.47, respectively. The reliability of this questionnaire in the present study was 0.75 , using Cronbach's alpha method. 
UCLA Loneliness Scale. This scale, designed by Russell et al. (75), consists of 20 items, half of which are negative sentences and half are positive ones. Each item is scored on a 4-point Likert scale, ranging from "never" to "always". The minimum and maximum scores are 20 and 80, respectively, with higher score indicating higher feelings of loneliness, and vice versa. The validity of the test is reported by Russell et al. using the test-retest method to be 0.89 . Hojjati et al. (76) reported Cronbach's alpha for this scale to be 0.89. Hojjati et al, also reported the Cronbach's alpha coefficients for this scale through the test-retest method with a time interval of two weeks were obtained 0.91 . The reliability of this questionnaire in the present study was 0.80 , using Cronbach's alpha method.

\section{Procedure}

The executive process of this research has been approved by the Ethics Committee of Kermanshah University of Medical Sciences under No. IR.KUMS.REC.1400.52. All procedures were carried out an adequate understanding and each participant provided their informed consent prior to the study. The study was conducted in accordance with the Declaration of Helsinki relative to clinical non-interventional research. After obtaining the necessary permits we conducted the preliminary stage of the research. During this stage, we designed the aforementioned questionnaires in the form of online ones. Participants were also asked to answer preliminary questions concerning inclusion criteria, and those who met the inclusion criteria were allowed access to the main questionnaires. One of the advantages of conducting this study online was that the questionnaires were designed in such a way that they would not be sent until they were fully answered. Therefore, there was no missing data. Finally, reviewing 530 questionnaires completed by the participants, we discarded 41 distorted questionnaires (for reasons such as age outside the scope of this study, and suffering from debilitating mental and physical illnesses) and analysed 489 questionnaires as the final sample of the research. The data obtained from the questionnaires were analysed using Pearson correlation coefficient and path analysis in SPSS-21 and LISREL-10.2 software.

\section{Results}


Table 2

shows the descriptive information including mean and standard deviation for research variables. In addition, Pearson correlations are reported to determine the relationship all variables included in the path model. The mean and standard deviation of death anxiety are 48.76 and 12.06, respectively. The correlation coefficient of death anxiety with life meaning was -0.36 , with social support was -0.15 , with Self-care was -0.24 , with psychological well-being was 0.32 , with Loneliness was 0.33 , and with depression was 0.34 . All these coefficients are significant at the level of 0.01 . More details are shown in Table 1.

Table 1 Descriptive statistics for research variables and correlation coefficient between them

\begin{tabular}{|c|c|c|c|c|c|c|c|c|}
\hline \multirow[t]{2}{*}{ variable } & \multirow[t]{2}{*}{ M } & \multirow[t]{2}{*}{ SD } & \multicolumn{6}{|c|}{ Correlation matrix } \\
\hline & & & 1 & 2 & 3 & 4 & 5 & 6 \\
\hline 1. life meaning & 41.11 & 8.70 & - & & & & & \\
\hline 2. Social support & 48.07 & 9.35 & $0.23^{\star \star}$ & - & & & & \\
\hline 3. Self-care & 57.29 & 7.45 & $0.12^{*}$ & 0.08 & - & & & \\
\hline 4. well-being & 53.06 & 9.59 & $0.33^{\star \star}$ & $0.36^{\star *}$ & $0.37^{\star \star}$ & & & \\
\hline 5. Loneliness & 64.42 & 10.67 & $-0.28^{\star *}$ & $-0.23^{\star *}$ & $-0.20^{\star *}$ & $-0.29^{* *}$ & & \\
\hline 6. depression & 43.07 & 10.50 & $-0.30^{\star *}$ & $-0.29^{\star *}$ & $-0.27^{\star *}$ & $-0.44^{\star *}$ & $0.40^{\star *}$ & \\
\hline 7. death anxiety & 48.76 & 12.06 & $-0.36^{\star \star}$ & $-0.15^{* *}$ & $-0.24^{\star *}$ & $-0.32^{* *}$ & $0.33^{\star *}$ & $0.34^{\star *}$ \\
\hline $\begin{array}{l}M=\text { mean, } S D=\text { star } \\
* P<0.05 ; * * P<0 .\end{array}$ & lard dev & ation & & & & & & \\
\hline
\end{tabular}

Table 2 Path coefficients for, psychological distress, social support, self-compassion, resilience, emotion regulation and $Q O L$ 


\begin{tabular}{|c|c|c|c|c|c|c|c|}
\hline Dependent & predictors & $\begin{array}{l}\text { Direct } \\
\text { effect }\end{array}$ & $\begin{array}{l}\mathrm{t}- \\
\text { value }\end{array}$ & $\begin{array}{l}\text { Indirect } \\
\text { effect }\end{array}$ & $\begin{array}{l}\mathrm{t}- \\
\text { value }\end{array}$ & $\begin{array}{l}\text { Total } \\
\text { effect }\end{array}$ & $\begin{array}{l}\mathrm{t}- \\
\text { value }\end{array}$ \\
\hline \multirow{5}{*}{$\begin{array}{l}\text { death } \\
\text { anxiety } \\
(\mathrm{R} 2=0.50)\end{array}$} & life meaning & -0.23 & -5.22 & -0.05 & -3.69 & -0.28 & -6.42 \\
\hline & Self-care & -0.10 & -2.38 & -0.04 & -2.89 & -0.14 & -3.15 \\
\hline & Well-being & -0.11 & -2.22 & -0.06 & -3.53 & -0.17 & -3.63 \\
\hline & Loneliness & 0.16 & 3.59 & -0.03 & -2.59 & 0.19 & 4.47 \\
\hline & depression & 0.14 & 2.88 & - & - & 0.14 & 2.88 \\
\hline \multirow[t]{5}{*}{ depression } & life meaning & -0.11 & -2.66 & -0.05 & -3.48 & -0.16 & -3.74 \\
\hline & $\begin{array}{l}\text { Social } \\
\text { support }\end{array}$ & -0.11 & -2.64 & -0.03 & -2.55 & -0.14 & -3.30 \\
\hline & Self-care & -0.10 & -2.49 & -0.03 & -2.32 & -0.13 & -3.07 \\
\hline & well being & -0.26 & -5.73 & -0.03 & -2.58 & -0.29 & -6.32 \\
\hline & Loneliness & 0.25 & 6.01 & - & - & 0.24 & 6.01 \\
\hline \multirow[t]{4}{*}{ Loneliness } & life meaning & -0.23 & -4.27 & - & - & -0.23 & -4.27 \\
\hline & $\begin{array}{l}\text { Social } \\
\text { support }\end{array}$ & -0.13 & -2.81 & - & - & -0.13 & -2.81 \\
\hline & Self-care & -0.11 & -2.51 & - & - & -0.11 & -2.51 \\
\hline & well being & -0.14 & -2.85 & - & - & -0.14 & -2.85 \\
\hline
\end{tabular}

Table 2 shows the direct, indirect, and total effects for the relationship of the variables in the model to death anxiety, depression and loneliness. According to the results of this table, life meaning $(\beta=-0.23)$, Social support $(\beta=-0.13)$, Self-care $(\beta=-0.11)$ and well-being $(\beta=-0.14)$ have a significant direct effect in the variance of elderly's loneliness. Also, life meaning $(\beta=-0.23)$, Self-care $(\beta=-0.10)$, well-being $(\beta=$ $-0.11)$, loneliness $(\beta=0.16)$ and depression $(\beta=0.14)$ have a significant direct effect in the variance of elderly's death anxiety. As well, life meaning $(\beta=-0.11)$, social support $(\beta=-0.11)$, self-care $(\beta=-0.10)$, well-being $(\beta=-0.26)$ and loneliness $(\beta=0.25)$ have a significant direct effect in the variance of elderly's depression.

According to the results of Table 2, the mediating role of loneliness in the relationship between life meaning, social support, self-care and well-being with death anxiety is significant and the mediating role of loneliness in the relationship between life meaning, self-care and well-being with depression is significant. Therefore, in addition to the direct effect of life meaning, social support, self-care and wellbeing on death anxiety and depression, their indirect effect was also confirmed by mediation alone of loneliness. Figure 2 shows the relationships obtained from path analysis with the standard parameter index and the t-value (in parentheses) on the paths. 
The goodness-of-fit indices reported in Table 3 show that the analyzed model has an excellent fit.

Table 3

The goodness of Fit Indices for the Models

\begin{tabular}{|c|c|c|c|c|c|c|c|c|c|}
\hline Index & $x^{2}$ & P-value & df & $x^{2 / d f}$ & RMSEA & $\mathrm{CFI}$ & AGFI & NFI & IFI \\
\hline Value & 0.53 & 0.47 & 1 & 0.53 & 0.00 & 0.99 & 0.99 & 0.99 & 0.99 \\
\hline
\end{tabular}

\section{Discussion}

The current study aims to investigate the relationship between the meaning of life, psychological wellbeing, self-care, and social capital with depression and death anxiety through the mediating role of loneliness in the elderly living in nursing homes. The pathway analysis indicated that the model proposed by this study properly fits in the studied sample. According to the obtained results, in addition to the direct effect of meaning of life, social capital, self-care and psychological well-being on death anxiety and depression, the indirect effect of them on death anxiety and depression through the mediating role of loneliness was confirmed. Accordingly, all hypotheses of this study were confirmed.

\section{The Relationship of Meaning of Life and Depression Through Loneliness}

The first hypothesis stating that the meaning of life is correlated with depression through loneliness was confirmed. In other words, individuals with a high level of meaning of life are less likely to feel loneliness, which in turn, leads them to experience lower level of depression. Although there is no study addressing this path, the finding of this study are consistent with that of previous studies $(23,43,44,50,52,77)$ in terms of the constituent relationships of this pathway. Regarding the interpretation of this finding, Kleftaras and Psarra (77) pointed out that individuals experiencing the high meaning of life, have usually a positive perception of their personal health level, experience lower level of anxiety and sleep disorder and, most importantly, have higher social performance, all of which will lead to lower level of depression. Besides, Steptoe and Fancourt (43) believe that individuals with a higher level of meaning and value in their life are probably more in touch with their friends, and are more likely to participate in social and cultural events. The idea that they feel they are doing valuable things not only is the result of this social participation but also makes them stay involved in personal and social relationships, thus experiencing a lower feeling of loneliness. Ultimately, conducting a 12-year longitudinal study on the relationship between loneliness and depression, Lee et al. (2021) stated in the interpretation of the mentioned relationship that loneliness can lead to cognitive dysfunction, such as increased vigilance towards 
threatening social stimuli and negative cognitive bias. Lonely individuals are more likely to expect negative social interactions, reminiscence negative social memories, and negatively evaluate themselves and their social context. Loneliness can lead to negative thoughts about self and is accompanied by depression. Experiencing meaningful companionship, belonging, and communication has lots of advantages, and a reduced level of each leads to depression. Loneliness can also have biological effects on responding stress, such as disruption in the immune system and hypothalamic-pituitary-adrenal (HPA) axis, which, in turn, may contribute to depression. In general, it can be concluded that a high level of meaning in life reduces the risk of depression in the elderly, keeping them involved in meaningful and valuable social relationships and improving the physiological performance of their body.

\section{The Relationship of Psychological Well-Being and Depression Through Loneliness}

The second hypothesis stating that psychological well-being is correlated with depression through loneliness was confirmed. In other words, individuals with high psychological well-being are less likely to experience feeling of loneliness, which in turn, leads them to experience lower level of depression. Even though no study has investigated this path, the finding of this study are consistent with that of previous studies $(25,26,45,46)$ in terms of the constituent relationships of this pathway. In interpretation of this finding, Hemingway \& Jack (45) believe that three important parts of the elderly's well-being are maintained and developed in social communications. Hemingway and Jack believe that self-esteem, quality of life, and empowerment in old age may be increased through participating in communities and avoiding loneliness. They believe that the presence of the elderly in the community and avoiding isolation and loneliness are related to high well-being through the development of factors, such as collective and individual identity, taking a role in society, providing and receiving social support, friendship, inclusivity, and social connection. In addition, Dhara \& Jogsan (25) stated that the relationship of the elderly with their family members seems to be of the essential factors in the relationship between depression and well-being. They believe that due to the lack of proper caring conditions by family members and being ignored by caregivers, the well-being of the elderly can be threatened which may lead to physical and mental problems, such as depression. To put it differently, they believe that a warm family atmosphere along with hospice care is necessary. Accordingly, it can be concluded that suitable social and family space as one of the essential elderly's well-being factors is related to the feeling of loneliness, which in turn, may be associated with lower level of depression.

\section{The Relationship of Self-Care and Depression Through Loneliness}

The third hypothesis of this study stating that self-care is correlated with depression through loneliness was confirmed. In other words, individuals with a high level of self-care are less likely to experience the feeling of loneliness, which in turn, may cause them to experience lower level of depression in 
them. Although no study has investigated this path, the finding of this study are consistent with that of previous studies $(28,47)$ in terms of the consistent relationships of this pathway. Regarding the interpretation of this finding, Canjuga et al. (78) believe that the elderly who have adequate knowledge and ability in self-care and an effective support system, are capable enough to increase their emotional, religious, and physical health, and to independently maintain their social participation, which in turn, lead them to experience a lower feeling of loneliness. According to Giardini et al. (79), however, insufficient self-care has some implications, such as reducing the level of health in individuals and may result in an increased level of disappointment, as the central core of depression. This type of disappointment usually reduces the incentive and tendency of individuals to do their desired activities and participate in social events, which leads to depression. This issue might lead to the formation of a downward spiral circle in which depression reduces self-care behaviors, which in turn increase the depression. In support of this claim, lovino et al. (80) indicated that depression symptoms, such as tiredness, reduced energy level, disappointment, along with reduced incentive, lead to loss of interest and desire to do things (tasks pertinent to self-care) that must be done to maintain health.

\section{The Relationship of Social Capital and Depression Through Loneliness}

The fourth hypothesis of this study, stating that social capital is related to depression through loneliness, was confirmed. In other words, individuals with high social capital are less likely to feel loneliness which, in turn, lead them to experience lower levels of depression. Although no study has investigated this path, the finding of this study are consistent with that of previous studies $(30-32,48,49)$ in terms of the consistent relationships of this pathway. Regarding the interpretation of this finding, Bai et al. (48) believe that elderly with a low level of social capital are more likely to experience loneliness due to lower functional ability, lower level of trust in others, and lower level of participation and communication. Similarly, Nyqvist et al. (49) stated that the elderly have a lower chance of maintaining their own social capital due to the higher risk of losing their friends and spouse. They believe that aging and loss of cognitive ability and functional limitation do not directly lead to loneliness but bring about depression, which per se results in the feeling of loneliness. In their points of view, there is a circular causality between depression and loneliness, because the feeling of loneliness probably brings about depression. They believe that the important factor in the reduced social capital, which leading to loneliness and depression is the loss of social participation among the elderly. In support of this interpretation, Sun et al. (31) also expressed that the most important reason behind higher social capital in the elderly (below 80 years old) is their ability for social interaction leading to the lower feeling of depression. Furthermore, in investigating the relationship between social capital and depression, Han et al. (32) have pointed out the important effect of trust and reciprocity and took advantages of the main effect model and the stressbuffering model for explaining this relationship. According to the main effect model, living in a highly trusting community leads individuals to have more loyalty to other members of the community, like neighbors and companions. In such a community, the tendency to help others can lay a foundation for a 
positive psychological condition via creating the feeling of safety, being accepted by the community, and self-worth, which per se decreases the probability of getting affected by depression. Besides, according to the stress-buffering model, the existence of social capital (trust and reciprocity) can prevent or alleviate negative emotional and cognitive responses to stressful incidents of life through a benign appraisal of the incidents. Such being the case will lead to lower mental health damage and a decreased probability of getting affected by depression.

\section{The Relationship of Meaning of Life and Death Anxiety Through Loneliness}

The fifth hypothesis of this study, stating that Meaning of life is correlated with death anxiety through the loneliness was confirmed. In other words, individuals with a higher meaning of life have a lower feeling of loneliness, which in turn, lead them to experience a lower death anxiety.

Although no study has investigated this path, the finding of this study are consistent with that of previous studies $(34,53,54)$ in terms of the consistent relationships of this pathway. Regarding the interpretation of this finding, Moore et al. (81) expressed that it seems that individuals with a higher meaning of life understand the high meaning life clearly, explain the essence of life based on their own personal values, and are capable of recognize goals and values of survival and life, and for this reason, they can have a more realistic perspective, accept the death and the its pertinent issues easily, and experience lower death anxiety. According to the meaning management theory (82), the best way to alleviate death anxiety appears to be searching for the meaning of life. This model also states that individuals aspire to live a more meaningful life, and focusing on positive growth seems better than searching for a defense mechanism against death anxiety. In other words, if individuals believe that their life is meaningful and they play an important part in their community, they will probably not experience being threatened with an inevitable death. In addition, according to the Terror Management Theory (83), the elderly with higher feelings of loneliness have lost their bonding with the common values of their own culture, which In turn leads the elderly to feel that the world is not particularly ordered and have no meaningfulness, which may make them vulnerable to death anxiety.

\section{The Relationship of Psychological Well-Being and Death Anxiety Through Loneliness}

The sixth hypothesis stating that psychological well-being is correlated with death anxiety through loneliness was confirmed. Indeed, individuals with higher psychological well-being have a lower feeling of loneliness, which in turn caused them to feel lower level of death anxiety. Although no study has investigated this path, the finding of this study are consistent with that of previous studies $(45,46,53,54,84)$ in terms of the consistent relationships of this pathway. Regarding the interpretation of this finding, we can say that based on the existentialism theory (85), the awareness of an 
individual regarding the death issue is the most important factor in the highest level of psychological well-being. According to this theory, individuals with a higher level of psychological well-being focus more on the awareness of being alive when encountering the death issue. In this case, instead of thinking that life is a perpetual and immortal essence and being engrossed in it, they are aware that they are living and can take advantages of being alive. According to what was mentioned before (45), the elderly with higher well-being are present in society and have a more social role. In this case, we can probably assert that this the concentration on being alive, increases the tendency to use life properly, as well as the tendency to social participation among the elderly, and maintains the bonding with the common values of their own culture, and for these reasons, decrease their death anxiety.

\section{The Relationship of Self-Care and Death Anxiety Through Loneliness}

The seventh hypothesis of this study stating that self-care is correlated with death anxiety through loneliness was confirmed. Indeed, individuals with higher self-care have a lower feeling of loneliness, which in turn causes them to experience lower death anxiety. Although no study has investigated this path, the finding of this study are consistent with that of previous studies $(37,53,54)$ in terms of the consistent relationships of this pathway. In interpretation of this finding, we again refer to Canjuga et al. (78), based on which, individuals with higher self-care have the required ability to maintain emotional, religious, and physical health, which can be correlated with their awareness of being alive and using this mortal essence. In addition, individuals with lower self-care can experience consequences like decreased health that can convey the meaning of forthcoming death in their minds. Thereby, such individuals are less likely to experience death anxiety, which leads to lower level of depression among them.

\section{The Relationship of Social Capital and Death Anxiety Through Loneliness}

The eighth hypothesis of this study, stating that social capital is related to death anxiety through loneliness, was confirmed. To put it differently, individuals with high self-care have a lower feeling of loneliness, which lead them to experience lower death anxiety. Although no study has investigated this path, the finding of this study are consistent with that of previous studies $(38,53,54)$ in terms of the consistent relationships of this pathway. In interpreting this finding, we can again refer to the previously provided interpretations. In this case, individuals with lower social capital are less able to experience social interaction, trust, and reciprocity, and will probably have a more feeling of loneliness. Such loneliness deprives them of engaging in a social condition, feeling alive, and living a life as a mortal essence, which in turn leading to a higher experience of death anxiety.

\section{The Implications of the Current Study for Therapy}


Taking a glance at the aforementioned interpretations, we can find out a fundamental common issue among all of them, which is social participation, the opposite point of feeling loneliness. As indicated, the meaning of the elderly's life is formed by maintaining the social function, peer relationships, companionship, belonging, and connection. Their social well-being consisting of self-esteem, quality of life, and empowerment is satisfied thanks to their social relations, social participation, and receiving social support. Meanwhile, their self-care is closely correlated with maintaining the social participation, and their social capital is satisfied thanks to mutual trust, reciprocity, and social participation. Therefore, one of the fundamental variables in identifying and preventing depression and death anxiety is loneliness among the elderly, which could only be improved by elevating their social participation. For this reason, the current study can convey a clear message for the experts and therapists working with the elderly. This message is nothing but the application of interventions and therapeutic methods assuring the presence of the elderly in communities and their participation in different social issues.

One of the most effective therapies in this field can be reminiscence therapy. Reminiscence therapy includes discussion about activities, events, and past experiences with an individual or a group of people, and is usually conducted using reminder stimuluses like a picture, video, cooking appliances, etc. (3). Different studies have demonstrated that the participation of the elderly in meetings where they can reminisce their memories may increase their happiness (86) and decrease their depression $(87,88)$ and death anxiety $(89)$. Hence, holding social events where the elderlys are encouraged to tell their past memories, authorities can help the elderly to increase their meaning of life and well-being and provide them with social capital, and incentivize them for taking care of themselves for having a sufficient potential to take part in these social programs. Doing so, an important step can be taken towards decreasing depression and death anxiety in the elderly through alleviating their feeling of loneliness.

\section{The Limitations of the Current Study}

One of the limitations of this study is about the data collection method that was done using self-report questionnaires. Although providing useful information, sometimes, these questionnaires can reduce the validity of the obtained results. Besides, although path analysis is used in this study, the nature of the obtained relations is of correlative, not causal type. Due to the utilized statistical method and crosssectional study, casual interpretation of this type of study is not appropriate. In addition, this study was conducted on Iranians, and due to the profound cultural difference between the eastern and western communities, some considerations should be considered in generalizing these findings to other communities.

\section{Suggestions for Future Studies}

According to the mentioned limitations in the current study, it is proposed that future studies use highly precise tools under a condition with controlling disruptive variables for investigating the mentioned 
relationship in this study. Moreover, future studies could use a longitudinal design to consider the relationship between these psychological structures. In addition, re-conducting such studies in different cultural contexts will help to obtain more universal and exact findings in this field.

\section{Declarations}

\section{Ethics approval and consent to participate}

The executive process of this research has been approved by the Ethics Committee of Kermanshah University of Medical Sciences under No. IR.KUMS.REC.1400.52. All procedures were carried out an adequate understanding and each participant provided their informed consent prior to the study.

\section{Consent for publication}

Not applicable.

\section{Availability of data and materials}

The datasets used and/or analyzed during the current study are available from the corresponding author on reasonable request.

\section{Competing interests}

The authors have no conflicts of interest to declare.

\section{Funding}

The authors received no specific funding for this work.

\section{Authors' Contributions}

MYA, PJ and MRM helped design the study. MYA acquired and analyzed the data and wrote the original draft. PJ, MRM and SF contributed to conceptualization and critical revision of the manuscript. MRM helped data interpretation. PJ and MRM helped project administration, funding acquisition and supervision. SF and MRM reviewed and edited the English text. All authors read and approved the final manuscript

\section{Acknowledgements}

We sincerely thank all the elderly residents of the nursing home who participated in this study. We also thank the officials of the nursing home who cooperated well with us.

\section{References}


1. World Population Prospects. World Population Prospects 2019: Highlights (ST/ESA/SER. A/423) 978-92-1-004235-2) [Internet]. New York: United Nations, Department of Economic Social Affairs, Population Division. Retrieved from: 2019. Available from: https://population.un.org/wpp/Publications/Files/WPP2019_Highlights.pdf

2. World Health Organization. Mental health of older adults. World Health Organization. 2017.

3. Amani R, Majzoobi MR, Hadian Hamedani K. The Construction and validation of the elderly reminiscence questionnaire. J Aging Psychol. 2019;5(4):333-45.

4. Phongsavan P, Grunseit AC, Bauman A, Broom D, Byles J, Clarke J, et al. Age, gender, social contacts, and psychological distress: Findings from the 45 and up study. J Aging Health. 2013;25(6):921-43.

5. Jha AK, Ojha SP, Dahal S, Sharma P, Pant SB, Labh S, et al. Prevalence of mental disorders in Nepal: Findings from the pilot study. J Nepal Health Res Counc. 2019;17(2):141-7.

6. Benbow SM. Older people, mental health and learning. Int Psychogeriatr. 2009;21(5):799-804.

7. Andreas S, Schulz H, Volkert J, Dehoust M, Sehner S, Suling A, et al. Prevalence of mental disorders in elderly people: The European MentDis_ICF65+ study. Br J Psychiatry. 2017;210(2):125-31.

8. Barua A, Ghosh MK, Kar N, Basilio MA. Prevalence of depressive disorders in the elderly. Ann Saudi Med. 2011 Dec;31(6):620-4.

9. Sarokhani D, Parvareh M, Dehkordi AH, Sayehmiri K, Moghimbeigi A. Prevalence of depression among iranian elderly: systematic review and meta-analysis. Iran J Psychiatry. 2018;13(1):55-64.

10. Seo H, Lee GJ, Shon H-C, Kong HH, Oh M, Cho H, et al. Factors affecting compliance with weightbearing restriction and the amount of weight-bearing in the elderly with femur or pelvic fractures. Ann Rehabil Med. 2020;44(2):109-16.

11. Banjongrewadee $\mathrm{M}$, Wongpakaran $\mathrm{N}$, Wongpakaran T, Pipanmekaporn $\mathrm{T}$, Punjasawadwong $\mathrm{Y}$, Mueankwan S. The Role of perceived stress and cognitive function on the relationship between neuroticism and depression among the elderly: A Structural equation model approach. BMC Psychiatry. 2020;20(1):1-8.

12. Aajami Z. Relationship between depression and cognitive impairment among elderly: A CrossSectional study. J Caring Sci. 2020;9(3):148-53.

13. Zis P, Daskalaki A, Bountouni I, Sykioti P, Varrassi G, Paladini A. Depression and chronic pain in the elderly: links and management challenges. Clin Interv Aging. 2017 Apr;12:709-20.

14. Kim H, Kim HS, Choi YM. Depression, interpersonal relationship, daily living stress, daily activity disorder, and health related quality of life from the participation of female elderly in health promoting program. Transylv Rev. 2017;1(2):44-56.

15. Lee SH. Moderating effects of interpersonal relation and social network on the relationship between depression and health behavior in elderly. J Digit Converg. 2017;15(9):397-406.

16. Yusefi Afrashteh $M$, Sharifi K. The relationship between depression, perceived stress and social support with quality of life in elderly with Alzheimer's disease. Aging Psychol. 2015;1(2):1-10. 
17. Liu J-C, Chang L-Y, Wu S-Y, Tsai P-S. Resilience mediates the relationship between depression and psychological health status in patients with heart failure: A Cross-Sectional study. Int J Nurs Stud. 2015;52(12):1846-53.

18. Saini P, Patidar AB, Kaur R, Kaur M, Kaur J. Death anxiety and its associated factors among elderly population of Ludhiana city, Punjab. Indian J Gerontol. 2016;30(1):101-10.

19. Watter DN. Response and rebuttal to existential issues in sexual medicine: The Relation between death anxiety and hypersexuality. Sex Med Rev. 2018;6(2):336-7.

20. Rashedi V, Ebrahimi B, Sharif Mohseni M, Hosseini M. Death anxiety and life expectancy among older adults in Iran. J Caring Sci. 2020 Aug 18;9(3):168-72.

21. Bala R, Maheshwari SK. Death anxiety and death depression among elderly. Int J Psychiatr Nurs. 2019;5(1):55-9.

22. Nal B, Aydın Avcı I, Ayyildiz M. The Correlation between death anxiety and anxiety in elderly with chronic obstructive pulmonary disease. Prog Health Sci. 2016 Jun 30;6(1):63-9.

23. Hedayati MAM, Khazaei MAM. An Investigation of the relationship between depression, meaning in life and adult hope. Procedia-Soc Behav Sci. 2014;114:598-601.

24. Steger MF, Frazier P. Meaning in life: One link in the chain from religiousness to well-being. $J$ Couns Psychol. 2005 Oct;52(4):574-82.

25. Dhara D, Jogsan YA. Depression and Psychological Well-being in Old Age. J Psychol Psychother. 2013;3(3):Article 1000117.

26. Jena N, Das S, Deo HK. Quality of Life, psychological well-being and depression among elderly: a Co relational study. Glob J Intellect Dev Disabil. 2018;4(2):39-44.

27. Karademas EC. Positive and negative aspects of well-being: Common and specific predictors. Personal Individ Differ. 2007 Jul 1;43(2):277-87.

28. Isik K, Cengiz Z, Doğan Z. The relationship between self-care agency and depression in older adults and influencing factors. J Psychosoc Nurs Ment Health Serv. 2020;58(10):39-47.

29. Chen MF, Wang RH, Hung SL. Predicting health-promoting self-care behaviors in people with prediabetes by applying Bandura social learning theory. Appl Nurs Res. 2015 Nov 1;28(4):299-304.

30. Cao W, Li L, Zhou X, Zhou C. Social capital and depression: Evidence from urban elderly in China. Aging Ment Health. 2015 Jan 1;19(5):418-29.

31. Sun J, Xiao T, Lyu S, Zhao R. The relationship between social capital and depressive symptoms among the elderly in China: The mediating role of life satisfaction. Risk Manag Healthc Policy. 2020 Mar 18;13:205-13.

32. Han KM, Han C, Shin C, Jee HJ, An H, Yoon HK, et al. Social capital, socioeconomic status, and depression in community-living elderly. J Psychiatr Res. 2018 Mar 1;98:133-40.

33. Putnam RD. Bowling alone: The Collapse and revival of American community. New York: Simon \& Schuster; 2000. 
34. Zhang J, Peng J, Gao P, Huang H, Cao Y, Zheng L, et al. Relationship between meaning in life and death anxiety in the elderly: self-esteem as a mediator. BMC Geriatr. 2019 Nov 12;19(1):1-8.

35. Nagaraj M, Gerontology D. Death anxiety and psychological wellbeing of institutionalized elderly: Relationship, association, and influences of demography. Indian J Gerontol. 2019;33(3):255-67.

36. Yousefi Afrashteh M, Masoumi S. Psychological well-being and death anxiety among breast cancer survivors during the Covid-19 pandemic: the mediating role of self-compassion. BMC Womens Health. 2021 Nov 3;21(1):1-8.

37. Majidi S, Bolourchifard F, Esmaeili R, Zolghadr Z. The Correlation between death anxieties with selfcare in elderly patients with chronic obstructive pulmonary disease referring to masih daneshvari hospital, 2018. J Gerontol. 2019 Oct 1;4(2):1-8.

38. Ebrahimi B, Hosseini M, Rashedi V. The Relationship between Social Support and Death Anxiety among the Elderly. Shahid Sadoughi Univ Med Sci. 2018;4(2):37-42.

39. de Jong Gierveld J, van Tilburg TG. Social isolation and loneliness. In: Encyclopedia of Mental Health. Elsevier; 2016. p. 175-8.

40. Theeke LA. Predictors of loneliness in US adults over age sixty-five. Arch Psychiatr Nurs. 2009;23(5):387-96.

41. Yang K, Victor C. Age and loneliness in 25 European nations. Ageing Soc. 2011 Nov 9;31(8):136888.

42. Tian Q. Intergeneration social support affects the subjective well-being of the elderly: Mediator roles of self-esteem and loneliness. J Health Psychol. 2016;21(6):1137-44.

43. Steptoe A, Fancourt D. Leading a meaningful life at older ages and its relationship with social engagement, prosperity, health, biology, and time use. Proc Natl Acad Sci U S A. 2019 Jan 22;116(4):1207-12.

44. Higuchi M. Managing loneliness in the elderly and finding meaning in ageing. J Compr Nurs Res Care. 2018;3(1):Article 125.

45. Hemingway A, Jack E. Reducing social isolation and promoting well being in older people. Qual Ageing Older Adults. 2013;14(1):25-35.

46. Stocker CM, Gilligan M, Klopack ET, Conger KJ, Lanthier RP, Neppl TK, et al. Sibling relationships in older adulthood: Links with loneliness and well-being. J Fam Psychol. 2019;34(2):175-85.

47. Shamlou R, Nikpeyma N, Pashaeipour S, Sahebi L, Mehrgou Z. Relationship of loneliness and social isolation with self-care ability among older adults. J Psychosoc Nurs Ment Health Serv. 2021;59(1):15-20.

48. Bai Z, Wang Z, Shao T, Qin X, Hu Z. Association between social capital and loneliness among older adults: A Cross-Sectional study in Anhui Province, China. BMC Geriatr. 2021 Dec 1;21(1):1-10.

49. Nyqvist F, Cattan M, Andersson L, Forsman AK, Gustafson Y. Social capital and loneliness among the very old living at home and in institutional settings: A comparative study. J Aging Health. 2013 Sep $29 ; 25(6): 1013-35$. 
50. Lee SL, Pearce E, Ajnakina O, Johnson S, Lewis G, Mann F, et al. The association between loneliness and depressive symptoms among adults aged 50 years and older: a 12-year population-based cohort study. Lancet Psychiatry. 2021 Jan 1;8(1):48-57.

51. Grover S, Avasthi A, Sahoo S, Lakdawala B, Dan A, Nebhinani N, et al. Relationship of loneliness and social connectedness with depression in elderly: A Multicentric study under the aegis of Indian Association for Geriatric Mental Health. J Geriatr Ment Health. 2018;5(2):99-106.

52. Domènech-Abella J, Lara E, Rubio-Valera M, Olaya B, Moneta MV, Rico-Uribe LA, et al. Loneliness and depression in the elderly: the role of social network. Soc Psychiatry Psychiatr Epidemiol. $2017 \mathrm{Apr}$ 1;52(4):381-90.

53. Jamadar C, Chawla S. Effect of loneliness on death anxiety among elderly people. Int J Indian Psychólogy. 2020;8(2):665-72.

54. Obaid Jumaa A. Psychological loneliness and its relationship to death anxiety in the elderly. Turk J Comput Math Educ TURCOMAT. 2021 Apr 11;12(4):1218-28.

55. Pinson MW. Effect of loneliness on older adults' death anxiety. University of North Texas; 2010.

56. Hooman HA. Structural equation modeling with LISREL application. 5th ed. Thran, Iran: SAMT; 2012.

57. Steger MF. MLQ description scoring and feedback packet. Pers Corresp. 2010;

58. Steger MF, Shin JY. The relevance of the Meaning in Life Questionnaire to therapeutic practice: A look at the initial evidence. Vol. 33, International Forum for Logotherapy. Viktor Frankl Inst of Logotherapy; 2010. p. 95-104.

59. Steger MF, Kashdan TB. Stability and specificity of meaning in life and life satisfaction over one year. J Happiness Stud. 2007;8(2):161-79.

60. Steger MF, Frazier P, Oishi S, Kaler M. The Meaning in life questionnaire: Assessing the presence of and search for meaning in life. J Couns Psychol. 2006;53(1):80-93.

61. Mesrabadi J, Jafariyan S, Ostovar N. Discriminative and construct validity of meaning in life questionnaire for Iranian students. Int J Behav Sci. 2013;7(1):83.

62. Piri M, Homayouni Bakhshayes N, Enayat B. Structural equation modeling of the relationship between the strategies of thought control and meaning in life and the students' academic performance. J Instr Eval. 2016;9(35):155-69.

63. Ryff CD, Singer BH. Best news yet on the six-factor model of well-being. Soc Sci Res. 2006;35(4):1103-19.

64. Khanjani M, Shahidi S, Fathabadi J, Mazaheri MA, Shokri O. Factor structure and psychometric properties of the Ryff's scale of Psychological well-being, short form (18-item) among male and female students. Thoughts Behav Clin Psychol. 2014;9(32):27-36.

65. Söderhamn O, Evers G, Hamrin E. A Swedish version of the Appraisal of Self-care Agency (ASA) scale. Scand J Caring Sci. 1996;10(1):3-9.

66. Söderhamn U, Bachrach-Lindström M, Ek AC. Self-care ability and sense of coherence in older nutritional at-risk patients. Eur J Clin Nutr. 2008;62(1):96-103. 
67. Hashemlo L, Hemmati Maslakpak M, Khalkhali HR. The Effect of Orem's self-care program performance on the self-care ability in elderly. J Urmia Nurs Midwifery Fac. 2013;11(2):1-10.

68. Nahapiet J, Ghoshal S. Social capital, intellectual capital, and the organizational advantage. Knowl Soc Cap. 2009;23(2):119-58.

69. Ghalavandi H, Soltanzadeh V, Beheshti rad R. A causal model of the relationship between servant leadership, workplace spirituality, and social capital. J Exec Manag. 2013;5(9):94-9.

70. Beck AT, Steer RA, Brown GK. Beck depression inventory (BDI-II). Vol. 10. Pearson; 1996.

71. Bayani AA, Ranjbar M, Bayani A. The Study of relationship between Ssocial problem-solving and depression and social phobia among students. J Mazandaran Univ Med Sci. 2012;22(94):91-8.

72. Tarsafi M, Kalantarkousheh SM, Lester D. Exploratory factor analysis of the defeat scale and its relationship with depression and hopelessness among Iranian University Students. 2015;

73. Templer DI. The contruction and validation of a Death Anxiety Scale. J Gen Psychol. 1970;82(2 d Half):165-77.

74. Rajabi GH, Bahrani M. Item factor analysis of death anxiety scale questions. J Psychol. 2002;5(4):331-44.

75. Russell D, Peplau LA, Cutrona CE. The revised UCLA Loneliness Scale: Concurrent and discriminant validity evidence. J Pers Soc Psychol. 1980;39(3):472-80.

76. Hojjati H, Koochaki G, Sanagoo A. The Relationship between loneliness and life satisfaction of the elderly in Gorgan and Gonbad cities. J Res Dev Nurs Midwifery. 2012;9(1):61-8.

77. Kleftaras G, Psarra E. Meaning in life, psychological well-being and depressive symptomatology: A Comparative study. Psychology. 2012;3(4):337-45.

78. Canjuga I, Železnik D, Neuberg M, Božicevic M, Cikac T. Does an impaired capacity for self-care impact the prevalence of social and emotional loneliness among elderly people? Work Older People. 2018 Nov 22;22(4):211-23.

79. Giardini A, Pierobon A, Callegari S, Caporotondi A, Stabile M, Avvenuti G, et al. Optimism may protect chronic heart failure patients from depressive symptoms: Relationships between depression, anxiety, optimism, pessimism and illness perception. Psicoter Cogn E Comportamentale. 2017;23(1):27-40.

80. Iovino P, De Maria M, Matarese M, Vellone E, Ausili D, Riegel B. Depression and self-care in older adults with multiple chronic conditions: A multivariate analysis. J Adv Nurs. 2020 Jul 1;76(7):166878.

81. Moore SL, Metcalf B, Schow E. The Quest for Meaning in Aging. Geriatr Nur (Lond). 2006 Sep;27(5):293-9.

82. Wong PTP. Meaning management theory and death acceptance. In: Tomer A, Eliason GT, Wong PTP, editors. Existential and spiritual issues in death attitudes. Lawrence Erlbaum Associates Publishers; 2008. p. 65-87.

83. McCoy SK, Pyszczynski T, Solomon S, Greenberg J. Transcending the self: A Terror management perspective on successful aging. In: Tomer A, editor. Death attitudes and the older adult. Brunner- 
Routledge.; 2000. p. 37-63.

84. Aghababaei N, Sohrabi F, Eskandari H, Borjali A, Farrokhi N, Chen ZJ. Predicting subjective well-being by religious and scientific attitudes with hope, purpose in life, and death anxiety as mediators. Personal Individ Differ. 2016 Feb;90:93-8.

85. Koestenbaum P. Is There an Answer to Death? Prentice Hall; 1976.

86. Majzoobi MR, Momeni K, Amani R, Hohhat Khah M. The Effectiveness of structured group reminiscence on the enhancement of the elderly's life quality and happiness. Dev Psychol $\mathrm{J}$ Iran Psychol. 2013;9(34):189-202.

87. Karimi H, Dolatshahee B, Momeni K, Khodabakhshi A, Rezaei M, Kamrani AA. Effectiveness of integrative and instrumental reminiscence therapies on depression symptoms reduction in institutionalized older adults: An Empirical study. Aging Ment Health. 2010;14(7):881-7.

88. Momeni K. The Effectiveness of structured group reminiscence on depression and self-esteem of older women. Int J Behav Sci. 2014;8(3):287-94.

89. Sheykhi A, Saeedinezhad F, Raiesi Z, Rezaee N. Effect of reminiscence therapy on death anxiety in retired elderly men: An Interventional study. Med-Surg Nurs J. 2020 Feb 29;9(1):Article e104172.

\section{Figures}

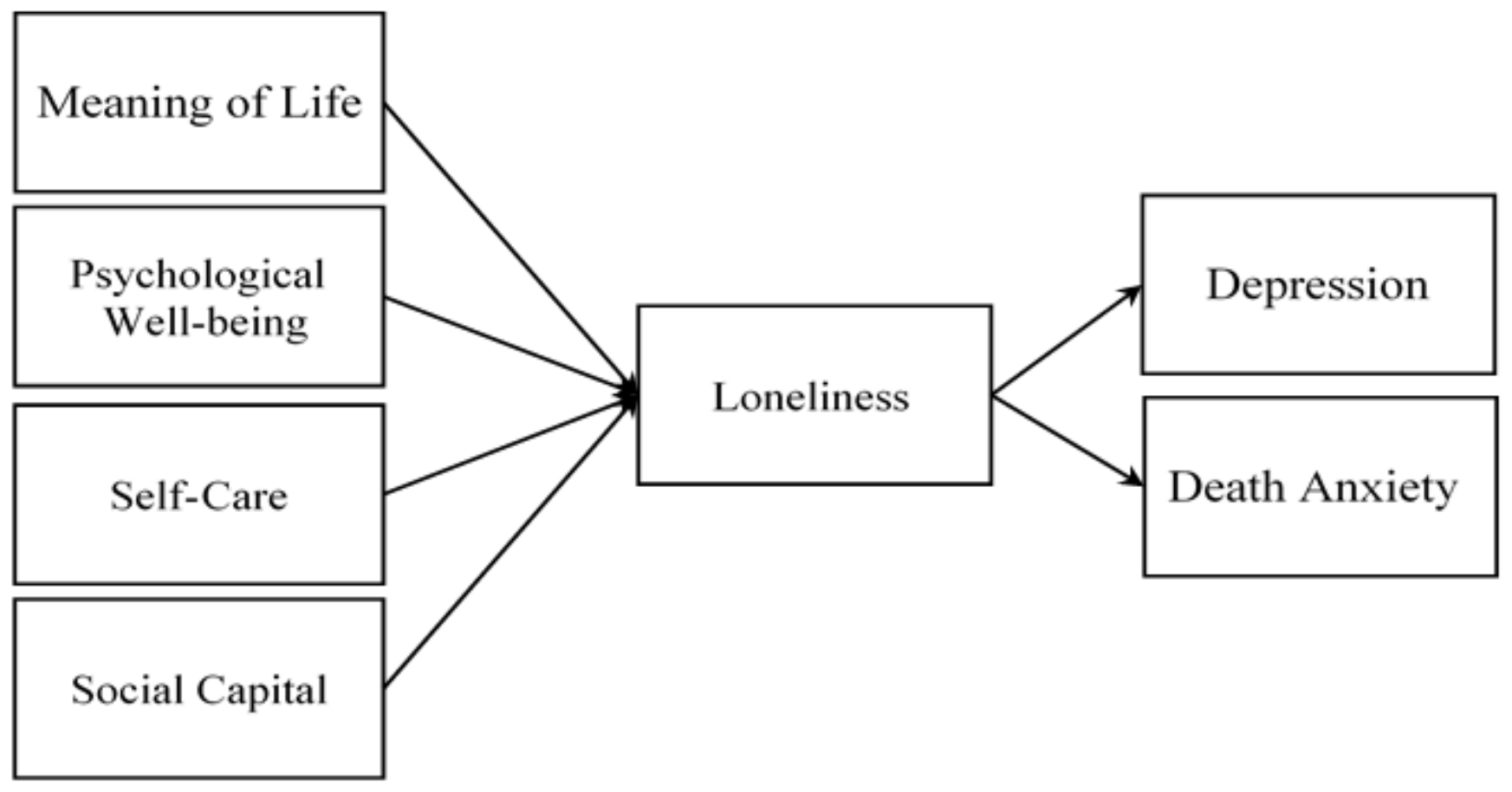

\section{Figure 1}

The hypothesized model of the relationship between the meaning of life, psychological well-being, selfcare, and social capital, with depression and death anxiety through the mediating role of loneliness 


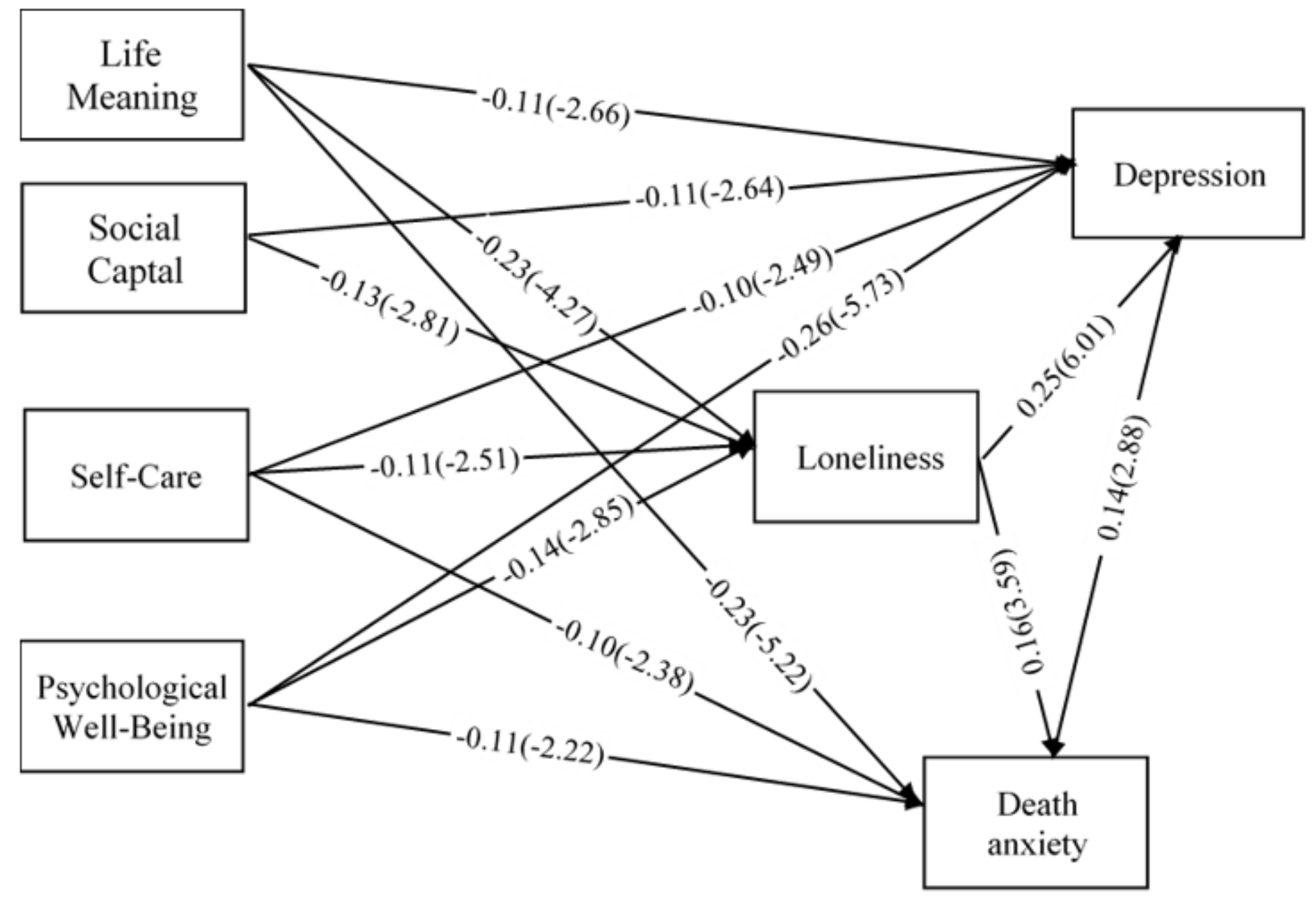

Figure 2

standard estimate (and t-value) for relationship between variables 